INRA Prod. Anim.,

2012, 25 (3), 245-258

\title{
Recherche en pathologie caprine : applications et perspectives
}

\author{
H. HOSTE ${ }^{1,2}$, N. EHRHARDT ${ }^{3}$, C. PARAUD ${ }^{3}$, A. RIEUX ${ }^{3}$, P. MERCIER ${ }^{3}$, S. VALAS ${ }^{3}$, \\ O. ANDREOLETTII, , F. CORBIERE ${ }^{1,2}$, F. SCHELCHER ${ }^{1,2}$, C. LACROUX $X^{1,2}$, \\ R. de CREMOUX ${ }^{4}$, M. ALVINERIE ${ }^{5,6}$, C. CHARTIER ${ }^{7}$ \\ ${ }^{1}$ INRA, UMR1225 Interactions Hôte Agents Pathogènes, 23 Chemin des Capelles, F-31076 Toulouse, France \\ 2 ENVT, UMR Interactions Hôte Agents Pathogènes, 23 Chemin des Capelles, F-31076 Toulouse, France \\ ${ }^{3}$ Anses, Laboratoire de Niort, 60 rue de Pied de Fond, F-79012 Niort, France \\ 4 Institut de l'Elevage, 23 Chemin des Capelles, F-31076 Toulouse, France \\ 5 INRA, UMR1331 ToxAlim, 180 chemin de Tournefeuille, F-31027 Toulouse, France \\ ${ }^{6}$ ENVT, UMR ToxAlim, 23 Chemin des Capelles, F-31076 Toulouse, France \\ 7 ONIRIS-Ecole Nationale Vétérinaire Agroalimentaire et de l'Alimentation, \\ Unité de Médecine des Animaux d'Elevage, F-44307 Nantes, France
}

Courriel:h.hoste@envt.fr

La chèvre, souvent désignée comme «la vache du pauvre», est aussi le parent pauvre des études en pathologie chez les petits ruminants. Les références caprines ne constituent que 25 à $30 \%$ des travaux cités pour les petits ruminants dans leur ensemble. De nombreux exemples soulignent pourtant les dangers potentiels de négliger les spécificités physiologiques, métaboliques ou comportementales des caprins dans la maîtrise des processus pathologiques. Ce constat justifie que les caprins fassent l'objet de recherches particulières dont les résultats en pathologie comparée conduisent à formuler des hypothèses de portée générale ${ }^{1}$.

Par rapport au mouton, la chèvre est souvent considérée comme une espèce «mineure», ce que tendent à démentir les statistiques mondiales, puisque les populations caprines et ovines sont respectivement évaluées à 910 millions et 1100 millions de têtes (FAOSTAT 2010 http://faostat.fao.org) avec une dynamique d'expansion pour les caprins. L'importance économique et sociétale de ces deux espèces de petits ruminants concernent avant tout les continents asiatique et africain qui comptent près de $95 \%$ des chèvres, mais moins de $70 \%$ des moutons de la planète.

Comme pour les ovins, ces chiffres globaux recouvrent une forte disparité de production. A l'échelle mondiale, la chèvre est d'abord élevée pour sa viande. Elle est aussi exploitée par les petits éleveurs avec un but mixte : elle assure au quotidien un apport de lait pour la famille, et sert occasionnellement de «porte monnaie sur pattes» en cas de besoin. Toutefois, les 14 millions de chèvres en Europe (environ 2\% des effectifs mondiaux) sont d'abord élevées pour leurs performances laitières. En cela, elles constituent une exception. Pour sa part, le cheptel français regroupe moins de 1,2 millions de têtes mais se situe à la toute première place pour la production de lait.

Malgré l'importance économique des caprins à l'échelle mondiale et en dépit de fortes particularités physiologiques, métaboliques ou de comportement alimentaire, les recherches sur les caprins restent en nombre faible par rapport aux ovins. Cette différence tient probablement au fait que plus de $30 \%$ de la population ovine se trouve en Australie, Nouvelle Zélande, Europe et en Amérique, ce qui n'est pas le cas des chèvres.

Cet article n'a pas pour objectif de dresser un panorama complet de la pathologie caprine, déjà fourni par des ouvrages de référence (Smith et Sherman 1994, Chartier 2010a). Il se propose plutôt, à partir de divers exemples, d'établir un bilan des recherches en cours en pathologie caprine et de leurs applications actuelles ou prochaines, ainsi que des orientations des travaux futurs. Ces exemples ont été choisis sur la base de plusieurs critères :

- Il s'agit d'abord exclusivement de pathologies infectieuses. Malgré leur fréquence et leur importance économique chez la chèvre laitière (Chartier 2010a), les maladies métaboliques ou nutritionnelles ne seront pas évoquées ici.

- Les exemples choisis correspondent aux principaux agents infectieux rencontrés en élevage caprin (prions, virus, bactéries, parasites protozoaires et métazoaires). Les pathologies décrites constituent des infections majeures affectant les chèvres et leur production,

\footnotetext{
${ }^{1}$ H. Hoste, F. Corbière, F. Schelcher, R. de Crémoux font partie de l'UMT Santé des Petits Ruminants dans le cadre de laquelle ce texte a été préparé
} 
ou illustrent l'intérêt des caprins en matière de modèle de pathologie comparée, afin de mieux comprendre la pathogénie de processus morbides communs aux deux espèces de petits ruminants et d'illustrer les spécificités caprines.

- Enfin, ces exemples correspondent à des thèmes de travaux en cours dans les principaux établissements français de recherche en médecine vétérinaire (INRA, Anses, Ecoles Vétérinaires, Institut de l'Elevage).

Les trois premières parties de cet article présentent un état des lieux des principaux travaux, connaissances actuelles et perspectives envisagées portant sur des pathologies caprines dont les critères de choix ont été exposés précédemment. Une dernière partie sera consacrée à une initiative récente dont l'objectif central est épidémiologique pour mieux identifier les pathologies dominantes chez les caprins et proposer des orientations futures de recherche.

\section{1 / Les prions et les virus}

\section{1 / Les encéphalopathies spon- giformes transmissibles : vers une approche génétique du contrôle et de l'éradication?}

Les Encéphalopathies Spongiformes Transmissibles (EST), ou maladies à prion, sont des affections neurodégénératives fatales observées chez un grand nombre de mammifères. Parmi les ruminants, les bovins (ESB), les moutons et les chèvres (tremblante) peuvent être atteints naturellement. Chez l'homme, différentes formes d'EST ont été décrites. La plus fréquente de ces formes humaines, baptisée maladie de Creutzfeldt Jacob sporadique (s-CJD), demeure une affection rare (environ un cas par million et par an) dont l'étiologie reste inconnue. En 1994 une nouvelle forme d'EST, baptisée variant de la maladie de Creutzfeldt Jacob (v-CJD) est apparue en Grande-Bretagne. Rapidement les données épidémiologiques et expérimentales ont permis d'établir que l'émergence de cette nouvelle maladie était liée à l'exposition des consommateurs à des produits contaminés par l'agent de l'ESB (Collinge et al 1996, Bruce et al 1997). Le nombre de patients affectés par le v-CJD reste à ce jour limité (moins de 250 cas). Toutefois dès 1996, la découverte du potentiel zoonotique des agents des EST a conduit les autorités sanitaires européennes à développer une politique de contrôle et d'éradication des maladies à prions chez les animaux de rente. Chez les caprins, en l'absence de moyens alternatifs de lutte, l'abattage total des cheptels atteints est la règle.
Le premier cas naturel d'EST caprine officiel fut rapporté en France en 1942 dans un troupeau mixte caprin/ovin au sein duquel des cas de tremblante ovine étaient régulièrement observés. Des cas cliniques d'EST caprine ont été depuis rapportés principalement en Europe (Wood et al 1992). Néanmoins, les caractéristiques spécifiques des EST chez les petits ruminants (longues durées d'incubation, symptômes souvent peu spécifiques, morbidité généralement faible) font de la surveillance clinique (ou surveillance passive) un outil peu sensible de détection. A partir de 2002, un système d'épidémiosurveillance actif des EST a été déployé sur tout le territoire de l'Union Européenne (UE). Cette surveillance est basée sur le criblage systématique d'une fraction des petits ruminants abattus pour la consommation ou équarris (Fediaevsky et al 2008).

Initialement destiné à déceler la survenue d'une épidémie d'ESB chez les petits ruminants, ce système, malgré ses imperfections, a permis d'améliorer notre perception de l'incidence et de la distribution des cas d'EST dans l'UE. A ce jour, plus d'un million de caprins ont été testés et 3292 cas d'EST caprines ont été rapportés, dont plus de $85 \%$ à Chypre, pays où la maladie est endémique. En France, peu de cas de tremblante caprine ont été décrits avant l'instauration du système actif de surveillance des EST. Dès sa mise en œuvre, un cas d'EST (identifié en 2002 et définitivement confirmé en 2005) a été détecté chez une chèvre née et abattue en France (Eloit et al 2005). Cette découverte a incité les autorités à tester de manière systématique l'ensemble des caprins abattus ou équarris sur le territoire national sur une période de plus de 18 mois. Ce dispositif n'a pas permis d'identifier d'autres cas d'EST caprines sur plus de 500000 animaux testés.

Entre 2002 et 2006, la prévalence estimée des cas de tremblante en France était de 5,7 à 12 cas pour 100000 petits ruminants testés. Bien que le nombre de cheptels atteints découverts chaque année en France reste limité, les conséquences socio-économiques liées à l'abattage total des troupeaux sont lourdes. Au-delà de nos frontières, la proportion de troupeaux atteints rend l'application d'une telle politique inacceptable pour des pays comme Chypre ou la Grèce. Par ailleurs, les performances du système d'épidémiosurveillance des EST chez les petits ruminants restent limitées et une politique d'éradication basée sur le seul abattage des troupeaux atteints détectés n'aurait, à moyen et long terme, que peu de chances de réussir. Dans ce contexte, le développement d'une approche alternative pour assainir les troupeaux atteints et maîtriser la maladie dans la population générale apparaît nécessaire.

Chez les caprins, des approches similaires à celles visant à identifier les allèles de résistance/sensibilité chez les ovins ont été appliquées (Billinis et al 2002, Vaccari et al 2006, Barillet et al 2009) (cf. encadré 1). Environ 25 poly-
Encadré 1. Pathogénie des Encéphalopathies Spongiformes Transmissibles (EST) et sélection génétique des hôtes résistants : l'exemple des ovins.

- Sur un plan moléculaire, l'événement clé du processus pathologique responsable des maladies à prion est la conversion d'une protéine de l'hôte (PrPC) en une isoforme anormale (PrPSc) qui s'accumule dans les tissus (Prusiner 1982, 1988). La PrPC est une protéine codée par le gène PRNP. Bien que relativement conservée chez les mammifères, la séquence de cette protéine présente un nombre important de polymorphismes dans une même espèce. Chez les ovins, les études menées en conditions naturelles d'exposition et chez des animaux expérimentalement exposés aux agents de la tremblante et de l'Encéphalopathie Spongiforme Bovine (ESB) ont permis d'établir que certains allèles du gène PRP ovin étaient associés à une très forte résistance à l'infection (ARR) alors que d'autres (ARQ et VRQ) conféraient aux individus porteurs une plus grande sensibilité à l'infection (Hunter et al 1997, Elsen et al 1999, Houston et al 2003). Sur la base de ces travaux, dès 1999 une politique basée sur la diffusion de l'allèle de résistance ARR et d'élimination des allèles $A R Q$ et $V R Q$ dans les cheptels atteints a été progressivement mise en œuvre dans différents états membres de l'Union Européenne. En 2001, des mesures visant à favoriser la diffusion de l'allèle ARR dans la population générale ovine ont été instaurés à l'échelle Européenne.

- La décennie écoulée a clairement démontré que l'allèle ARR ne conférait pas aux individus porteurs une résistance absolue à l'infection (Andreoletti et al 2006, Groschup et al 2007), mais permet à l'échelle du troupeau ou de la population de limiter la diffusion interindividuelle de l'agent infectieux avec comme conséquence une disparition des nouveaux cas de contamination (Hagenaars et al 2008, Melchior et al 2008). Le succès de cette politique de sélection génétique comme outil de contrôle et de prévention de la tremblante classique et de l'ESB chez les ovins ne s'est pas démenti. Toutefois, la découverte récente d'une forme atypique de tremblante contre laquelle l'allèle ARR ne confère aucune résistance particulière (Moum et al 2005, Moreno et al 2007) a amené les experts et les décideurs de la politique sanitaire en matière d'EST, à reconsidérer certains des objectifs à long terme de cette sélection génétique. 
morphismes en acides aminés ont été décrits chez les races les plus communément rencontrées en Europe. Certains de ces polymorphismes sont identiques à ceux rencontrés chez les ovins, d'autres sont spécifiques de l'espèce caprine. Malheureusement le polymorphisme Q171R, qui confère une forte résistance aux ovins, ne semble pas exister chez la chèvre. Toutefois, deux études indépendantes par comparaison à des cas témoins (l'une en France, l'autre en Italie), impliquant un nombre conséquent de chèvres issus d'un large panel de races, ont démontré que le polymorphisme Q222K est associé à un fort effet protecteur contre l'infection (effet protecteur du K222) (Billinis et al 2002, Vaccari et al 2006, Barillet et al 2009). De même, une étude chypriote semble indiquer que le polymorphisme S146N est associé à un effet protecteur contre l'infection par la tremblante naturelle (Papasavva-Stylianou et al 2007).

Malgré leurs limites, ces travaux représentent une ouverture vers une future gestion génétique de la lutte contre les EST chez la chèvre. Avant d'envisager la mise en œuvre d'une telle politique, les effets des polymorphismes aux codons 222 et 146 sur $i$ ) la sensibilité à l'infection et ii) la transmission interindividuelle de la maladie devront être validés. Les résultats de ces travaux ne sont pas attendus avant 3 à 5 ans. Ce délai représente une excellente opportunité pour recenser les caprins porteurs d'allèles d'intérêt et établir un schéma rationnel de diffusion. Les données actuelles indiquent en effet que la fréquence des individus porteurs de ces allèles est très limitée (quelques \%) en particulier dans certaines races (Billinis et al 2002, Vaccari et al 2006, Barillet et al 2009). Ce paramètre représente un écueil important pour le développement d'une politique de sélection à moyen et long terme, en particulier dans les pays où l'élevage caprin est peu structuré.

\section{2 / L'arthrite encéphalite caprine virale : une pathologie de maîtrise difficile}

Le terme d'Arthrite Encéphalite Caprine Virale (AECV) ne traduit que partiellement la réalité lésionnelle d'une pathologie mondialement distribuée et dominante dans la plupart des pays industrialisés, notamment en France où l'on estime à près de $90 \%$ le nombre d'élevages touchés. Cette maladie a pour étiologie une infection à lentivirus (le virus CAEV) et se manifeste chez un tiers des animaux infectés par un syndrome clinique très polymorphe incluant arthrite, mammite et pneumonie. De manière exceptionnelle, une forme nerveuse (encéphalomyélite) peut survenir chez la chevrette. Elle se transmet principalement par voie orale (colostrum et lait) chez le jeune et par voie respiratoire (sécrétions, aérosols) entre adultes (Blacklaws et al 2004). L'AECV induit des pertes économiques résultant d'une baisse de la production lactée, de troubles locomoteurs et de la reproduction, de causes de réformes anticipées. Par ailleurs, le dysfonctionnement des fonctions immunes des cellules dendritiques et de la lignée monocytes/macrophages, cibles majeures du virus CAEV, favorise l'établissement ou la propagation d'autres maladies (paratuberculose, tremblante...).

Des programmes nationaux de lutte et d'éradication ont été engagés sur la base d'un volontariat dans plusieurs pays européens, dont la France. En l'absence de traitement médical et de vaccin, leur principe repose sur une prophylaxie sanitaire chez les jeunes (isolement dès la naissance et allaitement à base de colostrum et de lait thermisés), l'exclusion des animaux symptomatiques et un contrôle sérologique périodique. Ces mesures de lutte permettent de limiter l'importance économique de l'AECV en réduisant la prévalence et l'expression clinique. En revanche, l'éradication de cette maladie demeure un objectif difficile à atteindre en raison de certaines conduites d'élevage (production intensive à vocation laitière) plus favorables à la propagation du virus, de la contamination inévitable des primipares après leur réintroduction dans le troupeau, de modes de transmission mineurs mais difficilement maîtrisables (voies utérine et mammaire), de séroconversions parfois tardives (de plusieurs mois à quelques années) et d'une charge virale généralement faible et inconstante (latence virale) qui limitent l'efficacité des outils de diagnostic.

La difficulté du contrôle de l'AECV résulte également de la connaissance relativement récente de l'étendue de la diversité génétique et antigénique des souches virales. Ce problème est amplifié par la capacité du virus CAEV et de son homologue chez le mouton, le virus Maedi-Visna (MVV), à franchir la barrière d'espèce. Les petits ruminants sauvages constituent également un réservoir viral (Erhouma et al 2008). Les virus CAEV et MVV sont aujourd'hui considérés comme une quasi-espèce dont les variants appartiennent à 5 génotypes et 19 sous-types, la plupart d'entre eux (3 génotypes et 14 sous-types) n'ayant été découverts qu'au cours de ces six dernières années. Les réactivités antigéniques inter-génotypes sont généralement faibles au cours de la phase précoce de l'infection (Lacerenza et al 2006).

Bien que les virus CAEV et MVV partagent de nombreuses propriétés bio- logiques, auxquelles s'ajoutent les similitudes remarquables des maladies induites, certains isolats MVV se distinguent par une propension à induire la forme nerveuse de la maladie (Oskarsson et al 2007), à se transmettre plus efficacement par voie mammaire chez la chèvre (Pisoni et al 2010), ou bien encore par leur capacité à reconnaître un récepteur fonctionnel à la surface de cellules d'espèces autres que celles des petits ruminants, ce qui confère in vitro un potentiel zoonotique à un virus CAEV pseudo-typé avec l'enveloppe d'un virus MVV (Hötzel et Cheevers 2001). Chez ces virus, le gène de l'enveloppe est la cible privilégiée d'évènements de recombinaison, et des virus chimères générés par recombinaison inter-génotype ont été décrits chez la chèvre dans les conditions naturelles (Pisoni et al 2007). L'importance épidémiologique des infections croisées soulève donc de nouvelles interrogations sur l'évolution des populations virales, de leur tropisme d'hôte et des maladies induites.

En conclusion, l'AECV est une maladie pour laquelle les moyens de lutte demeurent limités, mais qui peut être économiquement maîtrisée par une pression sanitaire continue. Il convient cependant de poursuivre une recherche permettant de fournir in fine une vision globale sur le risque sanitaire associé au potentiel évolutif des lentivirus des petits ruminants et à leur capacité d'adaptation à un nouvel hôte.

\section{2 / Les agents bactériens}

\section{1 / La paratuberculose : vers des possibilités de gestion opéra- tionnelle?}

La paratuberculose est une entérite chronique des ruminants domestiques et sauvages causée par Mycobacterium avium paratuberculosis (Map). Elle se caractérise par une période d'infection subclinique qui peut durer plusieurs années. Chez les caprins, la forme clinique se manifeste sur des animaux de plus de 2 ans par de l'amaigrissement progressif et irréversible, sans fièvre et avec un appétit conservé, souvent précédé par une baisse de la production laitière. Contrairement aux bovins, la diarrhée est exceptionnelle (uniquement chez 10 à 20\% des caprins) (Stehman 1996). Les connaissances scientifiques concernant la paratuberculose caprine sont limitées et largement extrapolées des connaissances obtenues chez les bovins. Les travaux de recherche de l'Anses portent sur trois composantes : les outils de diagnostic, l'épidémiologie et la gestion opérationnelle. 


\section{a) Outils de diagnostic}

Le diagnostic paraclinique de la paratuberculose fait appel à des outils direct et indirect.

La confirmation au laboratoire d'une forme clinique apparaît relativement aisée. A l'inverse, le dépistage des animaux infectés asymptomatiques, excréteurs ou non, est plus délicat. La principale difficulté pour évaluer les performances (sensibilité et spécificité) des outils de diagnostic tient au fait que la physiopathologie est complexe et que les différents tests n'explorent pas des événements synchrones. Ainsi, il n'existe pas actuellement de méthode de référence.

Malgré ces lacunes, il paraît possible d'évaluer les performances des outils de diagnostic grâce aux méthodes bayésiennes (Branscum et al 2005) dont le développement a été rendu possible par la mise au point de logiciels de calcul en libre accès. Une méthode bayésienne (logiciel WinBUGS) a permis d'évaluer les sensibilités et les spécificités de 2 tests de diagnostic de l'infection par Map (Mercier et al 2007, 2009a) : la culture fécale (diagnostic direct) et un test ELISA (diagnostic indirect) (ELISA paratuberculose anticorps bicupule ${ }^{\circledR}$, Institut Pourquier, Montpellier). Ils ont été appliqués sur des prélèvements (fèces et sérum) de 532 caprins issus de différents troupeaux de la région Poitou-Charentes. La sensibilité et la spécificité de la culture fécale ont été estimées respectivement à 34\% (31$38)$ et $99 \%(98-100)$ et à $53 \%(38-70)$ et $100 \%(99-100)$ pour le test ELISA.

Une autre étude (Mercier et al 2009b), réalisée également avec une méthode bayésienne (programme BLCM), a montré que les performances des tests variaient suivant l'âge des animaux. Sur des animaux âgés de 2 à 3 ans, la culture fécale et le même test ELISA ont fourni de meilleures estimations pour les sensibilités $(71 \%$ pour la culture fécale et $75 \%$ pour le test ELISA) et des estimations du même ordre de grandeur pour les spécificités $(97 \%$ pour la culture fécale et $96 \%$ pour le test ELISA) (tableau 1). L'infection par Map peut donc être détectée de façon plus fiable chez les caprins âgés de 2 à 3 ans.

La méthode ELISA est aujourd'hui celle ayant le meilleur ratio spécificité/sensibilité. En outre, la présence d'anticorps indique la probable incapacité de l'organisme à juguler l'infection par la réponse cellulaire et constitue la preuve de l'extension des lésions. Les animaux séropositifs ont donc un rôle épidémiologique important, et s'ils ne le sont pas déjà, deviendront excréteurs (Vialard 2002).

\section{b) Epidémiologie}

En matière d'épidémiologie, l'estimation de la prévalence d'infection par Map dans les cheptels caprins en France (Mercier et al 2010), était une première étape indispensable à la mise en place de plans de lutte. Cette estimation de la prévalence a été menée lors d'une enquête sérologique effectuée à l'aide du test ELISA commercial précité dont la sensibilité et la spécificité avaient été estimées préalablement. Cette étude a été conduite dans 105 troupeaux caprins répartis dans différentes régions, et sélectionnés aléatoirement parmi ceux soumis à la prophylaxie obligatoire contre la brucellose. Dans chaque troupeau, tous les animaux de plus de 6 mois ont été testés, soit 11847 chèvres. Les résultats sérologiques ont permis d'obtenir des prévalences apparentes, qui ont ensuite été transformées en prévalences vraies, en tenant compte de la sensibilité et de la spécificité du test. La prévalence au niveau des troupeaux était de 63\% (41-84) mais au niveau individuel elle n'était que de $7 \%$ (6-7), avec une prévalence intra-troupeau très variable. Ces résultats confirment que la paratuberculose est très présente dans les troupeaux caprins français.

\section{c) Gestion opérationnelle}

L'objectif est d'évaluer l'efficacité des différents moyens de lutte. Dans un premier temps, les travaux ont concerné l'évaluation de la vaccination. En France, la réglementation relative à la tuberculose bovine et caprine, limite l'usage de la vaccination anti-paratuberculeuse aux animaux de moins de 1 mois. Un vaccin inactivé contre la paratuberculose (Gudair $\AA$, CZ Veterinaria, Porino, Espagne) destiné aux petits ruminants est produit en Espagne. Une étude a été réalisée afin d'évaluer l'innocuité et l'efficacité du vaccin espagnol chez les caprins dans les conditions françaises d'utilisation. Dans deux troupeaux caprins atteints de paratuberculose, 115 chevreaux de moins de 1 mois ont été vaccinés et 124 chevreaux ont servi de témoins. Des prélèvements (fèces, sérum et sang) ont été effectués environ tous les 7 mois pendant 2,5 ans. L'impact de la vaccination sur les réactions locales, sur les taux de mortalité et de réforme, sur l'excrétion fécale de Map (mesurée par culture et PCR), et sur les réactions immunitaires (cellulaires et humorales) a été étudié. L'interférence de la vaccination sur le diagnostic de la tuberculose a également été explorée (par test intradermique) sur une partie des animaux à l'âge de 3,5 ans. Des réactions locales persistent chez $61 \%$ des chèvres 5,5 mois après la vaccination mais ont une taille modérée. A la fin de l'étude, sur l'ensemble de la cohorte, la vaccination a réduit la mortalité due à la paratuberculose de $47 \%$ et la réforme de $63 \%$. A l'âge de 23 mois, la prévalence des excréteurs est significativement plus faible chez les chèvres vaccinées (3\% vs $16 \%$ chez les chèvres non vaccinées). L'effet de la vaccination

Tableau 1. Sensibilité (Se) et Spécificité (Sp) exprimées en \% (entre parenthèses l'intervalle de confiance à 95\%) de 2 tests de diagnostic de l'infection par Mycobacterium avium paratuberculosis (Map) selon les différentes classes d'âge chez 412 chèvres (Mercier et al 2009b).

ELISA (recherche d'anticorps anti-Map dans le sérum) et culture (recherche de Map par mise en culture à partir des fèces).

\begin{tabular}{|c|c|c|c|c|c|}
\hline \multirow{2}{*}{ Se/Sp } & \multirow{2}{*}{ Test } & \multicolumn{4}{|c|}{ Age des chèvres } \\
\cline { 3 - 6 } & & $<1$ an & $1-2$ ans & $2-3$ ans & $>3$ ans \\
\cline { 3 - 6 } & & $(n=104)$ & $(n=104)$ & $(n=101)$ & $(n=103)$ \\
\hline \multirow{2}{*}{ Se } & ELISA & $1,6(0,2-21,8)$ & $4,3(0,6-70,4)$ & $75,5(44,5-96,2)$ & $5,5(0,8-68,8)$ \\
\cline { 2 - 6 } & Culture & $7,9(0,6-81,3)$ & $7,8(0,8-69,4)$ & $71,2(39,9-97,1)$ & $2,9(0,1-85,1)$ \\
\hline \multirow{2}{*}{ Sp } & ELISA & $97,6(66,0-99,8)$ & $51,5(12,7-98,2)$ & $95,9(88,8-99,4)$ & $79,3(22,6-98,9)$ \\
\cline { 2 - 6 } & Culture & $82,3(9,4-99,4)$ & $53,3(12,0-96,4)$ & $97,3(91,3-99,9)$ & $82,1(9,4-99,8)$ \\
\hline
\end{tabular}


sur les réactions immunitaires (cellulaires et humorales) est observé jusqu'à l'âge de 23 mois. A 3,5 ans, la vaccination n'interfère pas sur le diagnostic de la tuberculose.

La vaccination contre la paratuberculose par un vaccin inactivé réduit la mortalité ainsi que les réformes et limite le nombre d'excréteurs. Elle est donc un outil intéressant pour la maîtrise des formes cliniques.

\section{2 / Les infections mammaires : orientations des recherches}

Chez la chèvre, comme chez les autres espèces à vocation laitière, la maîtrise de la qualité sanitaire du lait et des produits laitiers est un enjeu majeur pour l'ensemble de la filière, de la production à la transformation. A ce titre, la qualité microbiologique du lait, matière première, et corollairement, le statut infectieux des animaux vis-à-vis des infections intra-mammaires, jouent un rôle essentiel.

Les recherches conduites sur ce sujet se sont d'abord intéressées à l'étiologie et à l'épidémiologie des mammites cliniques et subcliniques (Bergonier et al 2002) et au dépistage des infections (de Crémoux et al 2000). Témoin reconnu de l'inflammation mammaire chez la vache laitière, l'augmentation du nombre des cellules somatiques du lait a longtemps été considérée comme non interprétable chez la chèvre en raison du caractère apocrine de la sécrétion lactée (décapitation de la partie apicale des cellules sécrétrices) et de la présence de particules cytoplasmiques dans le lait. La généralisation, dans les années 1990, de techniques de comptages automatisées, basées sur la mise en évidence des noyaux cellulaires, l'adaptation de la calibration des appareils de comptage et de la gamme d'étalonnage, ont permis de reconsidérer cette assertion et d'envisager les Comptages de Cellules Somatiques (CCS) comme un outil potentiel de gestion sanitaire. Les seuils dynamiques d'interprétation des CCS individuels, à visée diagnostique (de Crémoux et al 1996) ou opérationnelle (Baudry et al 1999), établis alors, prévalent encore aujourd'hui. Des mesures de maîtrise ont été proposées en élevage, mais force est de constater qu'elles n'ont été que très partiellement adoptées par les producteurs et que, parallèlement, la qualité cellulaire des laits de tanks collectés par les entreprises laitières, s'est graduellement détériorée.

Ce bilan soulève de nombreuses questions d'une part, sur l'impact économique effectif des infections mammaires, en tant que moteur des actions en élevage et d'autre part, sur la nature, l'efficacité des mesures de maîtrise
Photo 1. Congestion, hyperkératose : l'impact des réglages et des dysfonctionnements des installations de traite sur les lésions des trayons et la santé mammaire demande des études spécifiques (crédit photo : $R$. de Crémoux, Institut de l'Elevage).

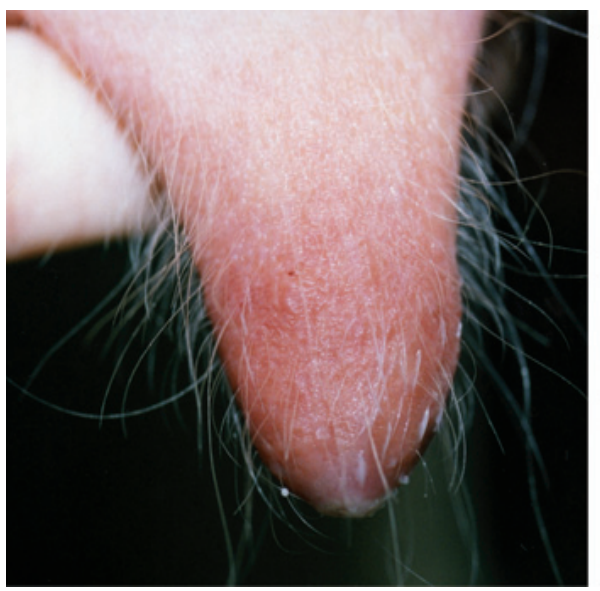

et leur adéquation avec les conduites d'élevage chez la chèvre. La mobilisation des chercheurs concerne ces deux aspects.

\section{a) Préciser l'impact sur la qualité technologique du lait}

Le dysfonctionnement de la glande mammaire induit par les mammites suscite, comme l'ont mis en évidence Baudry et al (1997), à la fois une chute de production et une modification de la composition du lait, facteur de dépréciation des produits tant sur le plan de la texture que des saveurs. Chez la chèvre cependant, il semble que les laits présentant une flaveur «chèvre» prononcée soient ceux qui présentent conjointement une teneur en matière grasse plus faible, un niveau cellulaire et un niveau

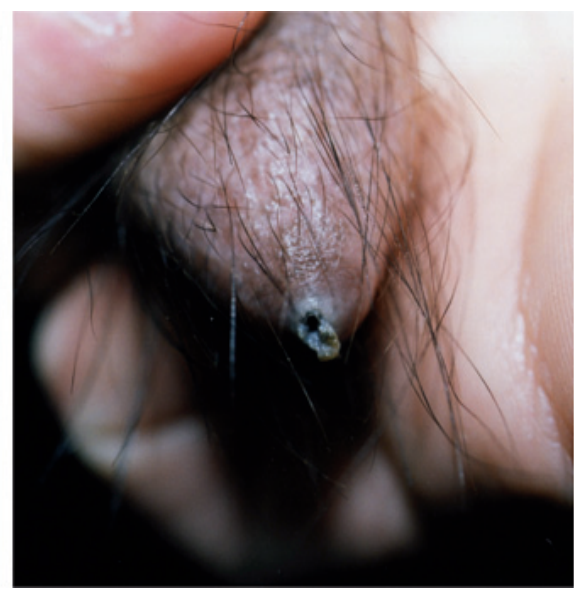

de lipolyse plus importants que les autres (Gay-Jacquin et al 1996, Jaubert et al 1996). Après affinage, les caractéristiques organoleptiques des fromages ne semblent pas détériorées (Morgan et Gaspard 1999). Ces résultats ont toutefois été obtenus pour des niveaux cellulaires inférieurs à 2 millions de cellules/mL, situation couramment rencontrée en élevages caprins, et demandent à être réévalués à partir de laits de tank présentant des niveaux plus élevés de CCS (3 millions et plus). Au-delà des aspects sensoriels, il s'agit aussi de quantifier l'impact de l'utilisation de tels laits sur les paramètres technologiques : vitesse de coagulation, rendement fromager, égouttage, etc. pour mieux appréhender les conséquences en transformation de statuts sanitaires dégradés.
Photo 2. Chevreaux atteints de cryptosporidiose (crédit photo: Anses, laboratoire de Niort).

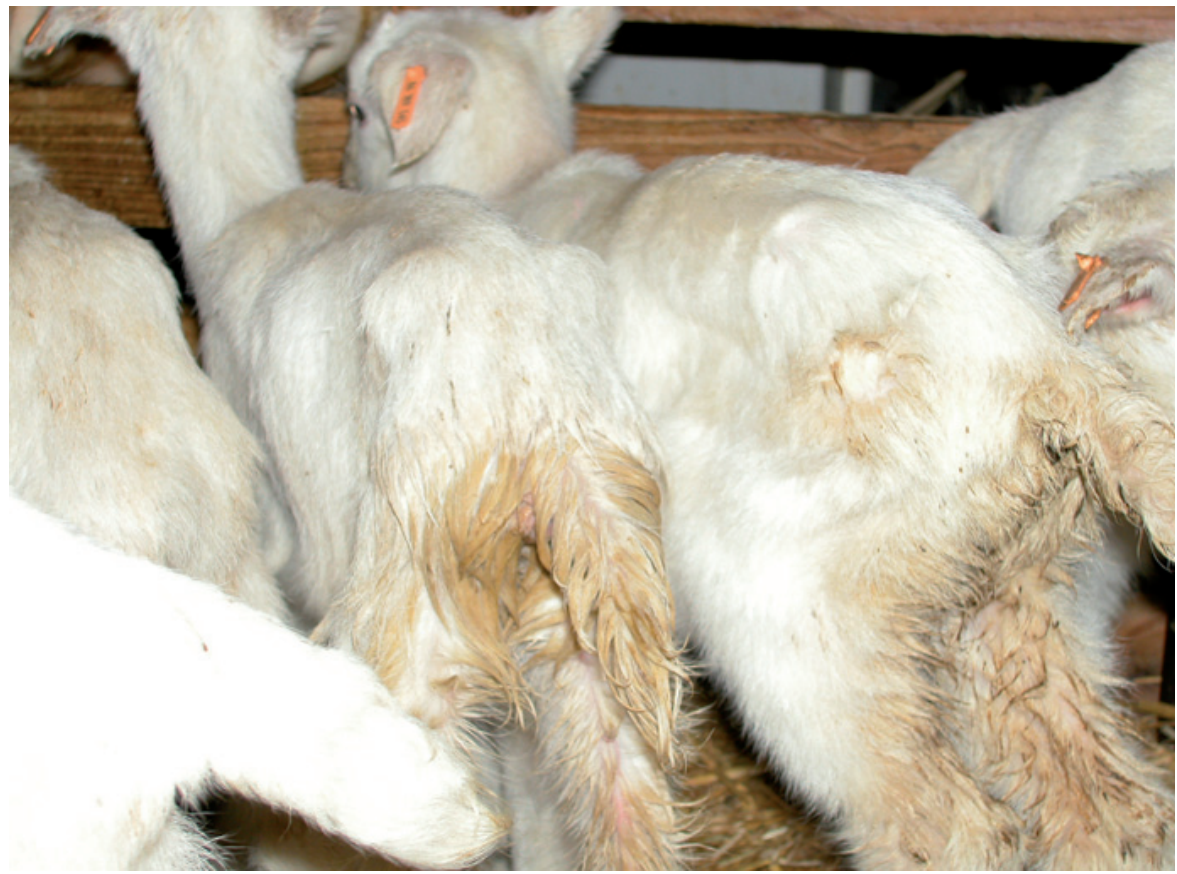


b) Définir et évaluer des stratégies de contrôle adaptées

La maîtrise des infections mammaires repose sur des principes similaires à ceux appliqués chez la vache laitière. L'écueil d'une extrapolation systématique entre espèces doit toutefois être évité (Raynal-Ljutovac et al 2007). Seules certaines mesures de gestion sanitaire seront abordées ici à titre d'illustration.

Cibler les mesures curatives. Une révision des règles pour décider des animaux à traiter ou à réformer (de Crémoux et al 2001) est désormais nécessaire en raison de l'évolution et de la diversité des protocoles de contrôles de performances proposés aux producteurs : prise en compte d'un nombre restreint de contrôles, adaptation des règles en cas de contrôles sur les traites du matin ou du soir, etc.

Améliorer la résistance aux mammites. Différents travaux ont été engagés depuis 2008 pour évaluer l'intérêt, la faisabilité et les modalités de mise en œuvre d'un outil de sélection fondé sur les CCS en vue de l'amélioration de la résistance aux mammites (Clément et al 2008). Ils portent sur l'évaluation des paramètres génétiques de la moyenne par Lactation des Scores de Cellules Somatiques (LSCS) résultant de la transformation logarithmique des CCS mensuels. L'héritabilité modérée mais homogène de ce paramètre $(0,20$ à 0,24 selon les races), sa répétabilité élevée entre rangs de lactation, sa faible corrélation génétique avec les caractères de production du lait (teneurs en matière grasse exceptées) et sa corrélation favorable avec certains caractères de morphologie mammaire comme le plancher de la mamelle, sont autant d'éléments en faveur de son intégration dans un index combiné et de son inclusion dans le programme national de sélection (Rupp et al 2011). La constitution et le suivi de lignées divergentes à l'unité expérimentale INRA de Bourges devraient permettre de préciser l'impact d'une telle sélection à la fois sur la fréquence des infections et sur les autres caractères d'intérêt laitier (production et morphologie) mais aussi de rechercher d'éventuels marqueurs biologiques précoces et fiables de l'inflammation de la mamelle dans le lait (Cebo et al 2009).

Améliorer les conditions de traite. Dans un modèle de mammites contagieuses, la traite constitue un élément clé dans la transmission des infections (Bergonier et al 2003). Or, les paramètres de traite (réglages de la machine à traire, temps de traite...) sont le plus souvent définis de manière empirique puis ajustés sur le terrain sans faire l'objet d'une validation scientifique systématique (Marnet 1998). En pratique, l'aptitude à la traite en relation avec les caractéristiques anatomo-fonctionnelles de la mamelle, la physiologie de l'éjection du lait interviennent dans la régulation de la production laitière et ont une incidence sur la réponse individuelle de l'animal face à des conditions de traite données. Les connaissances en la matière ne sont pourtant que récentes et encore partielles. La chèvre se singularise notamment par l'importance de la fraction de lait citernal $(70 \%$ du lait extrait contre environ $15 \%$ chez la vache et $35 \%$ chez la brebis), une forte flexibilité (compliance) de la mamelle, une moindre importance du réflexe neuroendocrinien et de la décharge d'ocytocine associée à l'éjection du lait et a contrario un rôle important de la tonicité du sphincter sur l'aptitude à la traite (émission du lait et débit) (Marnet 1998). En découle une grande capacité d'adaptation de la chèvre à des traites incomplètes, voire à une traite unique quotidienne (Marnet et Komara 2008) ou encore une approche de la stimulation de la mamelle avant la traite distincte de celle de la vache laitière (Collectif 2006).

Par ailleurs, une meilleure connaissance des cinétiques d'éjection du lait a d'ores et déjà permis de proposer de nouvelles normes en matière de matériel de traite (Billon et al 2002). Malgré d'indiscutables avancées dans le domaine de la traite, les informations font encore défaut sur les relations entre les réglages des installations de traite et l'état des trayons et plus largement l'état de santé de la mamelle (photo 1). Les modalités d'infection des primipares, considérées comme les plus sensibles aux pratiques de traite (de Crémoux et al 2001), nécessitent d'être plus particulièrement étudiées.

Prendre en compte l'évolution des conduites d'élevage et du contexte de production. Avec l'augmentation de taille des troupeaux, différentes conduites d'élevage se sont développées avec un objectif de simplification des pratiques et de limitation du temps de travail. C'est notamment le cas de la traite une fois par jour (monotraite) ou encore de l'allongement des lactations en l'absence de mise à la reproduction, conduite dite en «lactation longue», particulière à la chèvre, conduisant à des lactations d'au moins 16 mois pour les primipares et souvent de plus de 600 jours pour les multipares. Sur des durées courtes et/ou dans une population jeune caractérisée par une prévalence faible des infections, leurs impacts sur les CCS sont apparus modérés (Lefrileux et al 2008, Bergonier et al 2010) en comparaison des études menées chez la vache laitière. En revanche, leurs conséquences à long terme n'ont pas été évaluées ainsi que les implications possibles de ces changements de pratiques sur la conception du matériel de traite ou encore la sélection des animaux.

Les progrès dans la connaissance des infections mammaires et des CCS nécessitent une approche pluridisciplinaire s'appuyant sur une meilleure compréhension de la physiologie de la mamelle et de l'éjection du lait ainsi que des interactions entre la mamelle, les pratiques et le matériel de traite, en tenant compte des possibilités d'orientation de la sélection. Le poids économique et organisationnel de la maîtrise des mammites en élevage est également important à appréhender afin de pouvoir proposer des mesures adaptées aux structures et aux conduites de l'élevage caprin de demain.

\section{3 / Les parasites}

\section{1 / La cryptosporidiose : une pathologie sévère des chevreaux}

La cryptosporidiose est une parasitose du jeune animal causée par un protozoaire du genre Cryptosporidium. Longtemps considéré comme un parasite opportuniste, il est aujourd'hui reconnu comme un pathogène primaire per se. Son épidémiologie complexe, sa grande résistance dans le milieu extérieur et les difficultés de traitement ou de prévention en l'absence de molécules véritablement efficaces et autorisées chez les caprins rendent cette infection difficile à gérer. Les données sont généralement étayées chez les bovins mais rares ou absentes chez les caprins alors que cette pathologie revêt une gravité particulière chez le chevreau (photo 2). Lors d'épisodes cliniques, la morbidité peut atteindre $100 \%$ d'un lot et la mortalité $60 \%$, l'excrétion atteignant plusieurs millions d'oocystes par gramme de fèces (Chartier et al 1999). Chez la chèvre adulte, la prévalence d'infection et le niveau d'excrétion sont faibles (CastroHermida et al 2007), mais une augmentation d'excrétion est constatée autour de la mise bas (Castro-Hermida et al 2005). La mère, et surtout l'environnement contaminé (grand nombre d'oocystes émis et grande résistance dans le milieu extérieur), sont supposés être à l'origine de la contamination des jeunes.

Les premières études d'épidémiologie descriptive, fondées sur des méthodes de coloration, n'autorisaient pas la distinction des espèces en cause. C. parvum était alors considérée comme l'espèce pathogène des ruminants. Par la suite, des méthodes de caractérisation moléculaire ont montré la complexité du 
genre. Aujourd'hui, pour toutes espèces d'hôtes confondues, 20 espèces de Cryptosporidium spp et une quarantaine de génotypes ont été décrits (Xiao 2010). Toutefois, peu de données d'épidémiologie moléculaire sont disponibles chez les caprins. C. parvum est l'espèce majoritairement retrouvée chez le chevreau non sevré (Geurden et al 2008, Quílez et al 2008, Paraud et al 2009b). C. xiaoi, une espèce décrite chez les ovins, a récemment été identifiée chez des chevrettes de moins de 21 jours (Díaz et al 2010). Chez la chèvre adulte, Cama et al (2008) ont montré la présence de $C$. ubiquitum. La confirmation des espèces excrétées chez les caprins est actuellement en cours d'étude. Les premiers résultats d'un suivi longitudinal d'animaux, de la naissance à la première mise bas ont mis en évidence chez des chevrettes avant sevrage, une excrétion prépondérante de $C$. xiaoi accompagnée ou non de signes cliniques avec, en outre, un animal excrétant successivement $C$. parvum et C. xiaoi (Rieux, communication personnelle). Il est à noter que certaines espèces de cryptosporidies (principalement C. parvum) et sous-types (sous-types IIa et IId de $C$. parvum) précédemment isolés chez le chevreau sont potentiellement zoonotiques (Geurden et al 2008, Quílez et al 2008). Ces données sur le potentiel de transmission zoonotique des caprins sont à compléter.

Au chapitre de la prévention des épisodes cliniques, les facteurs de risque d'apparition de la cryptosporidiose ont été largement étudiés chez le veau laitier et très peu chez le chevreau (Delafosse et al 2006). Le constat de la difficulté de mettre en évidence des facteurs opérationnels pour les éleveurs a conduit à réaliser une étude sur les pratiques d'élevage du chevreau (Paraud et al 2010). Cette enquête réalisée dans le département des Deux-Sèvres a montré une grande diversité des pratiques et le plus souvent un décalage entre les recommandations d'hygiène et de soins aux nouveau-nés et les pratiques effectives. L'existence d'un risque avéré de cryptosporidiose lié aux pratiques reste à démontrer.

En matière de gestion médicale de la maladie, l'efficacité d'environ 140 molécules a été testée vis-à-vis de Cryptosporidium spp toutes espèces hôtes confondues. Deux molécules ont fait l'objet de la majorité des essais chez le chevreau: le lactate d'halofuginone et le sulfate de paromomycine. Seul le lactate d'halofuginone est disponible en France $\left(\right.$ Halocur $^{\circledR}$ ) pour le traitement de la cryptosporidiose du veau. Son utilisation est possible chez le chevreau mais présente des contraintes liées principalement au temps d'attente avant la commercialisation de la viande et à la gestion collective des pathologies dans cette espèce. Il est donc nécessaire de s'intéresser à des méthodes alternatives. L'administration préventive par le lait de remplacement d'un produit issu de la combustion de bois d'essences sélec-

Encadré 2. L’arsenal thérapeutique contre les Nématodes Gastro-Intestinaux (NGI) des chèvres.

- Depuis la mise sur le marché du premier anthelminthique $(\mathrm{AH})$ de synthèse (la phénothiazine, à la fin des années 1950), ces molécules ont été considérées comme le moyen principal, voire exclusif, de lutte contre les NGI chez les ruminants. Par la suite, l'industrie pharmaceutique a contribué à développer et commercialiser de nouvelles familles d'AHs. Au-delà des critères d'efficacité et d'absence de toxicité pour le consommateur (absence de résidus dans les produits d'origine animale), la tendance générale a été :

1) d'accroître le spectre d'activité sur divers helminthes :

2) de réduire la toxicité directe potentielle en augmentant les coefficients de sécurité et en réduisant les posologies utiles;

3 ) de prendre en compte des exigences sociétales nouvelles (possibles effets environnementaux):

4) de faciliter les conditions d'emploi de ces produits pour les éleveurs (Waller 2006).

- Cette démarche a abouti à l'établissement de 3 grandes familles d'AHs à large spectre incluant toutes les espèces de Nématodes parasites du tube digestif et de l'appareil pulmonaire mais aussi parfois certains Cestodes (ténias) ou Trématodes (douves) :

1) les benzimidazoles et probenzimidazoles ;

2) la famille des imidazothiazoles (lévamisole) et tetrahydropyrimidines (pyrantel et morantel) :

3) les lactones macrocycliques, regroupant avermectines et milbémycines.

- Cette classification par famille se fonde plus sur des mécanismes d'action (identifiés ou suspectés) sur les vers que sur des critères de proximité de structure biochimique.

Les innovations technologiques de la part de l'industrie pharmaceutique continuent puisque deux nouvelles classes de molécules AHs sont en voie de commercialisation, le monepantel (dérivé aminoacétonitrile ou AAD) et le derquantel (spiroindole) combiné à une avermectine, pour traiter les $\mathrm{NGI}$ des ruminants.

Cependant, la chèvre étant considérée comme une espèce "mineure» pour laquelle les retombées commerciales restent limitées, les demandes d'Autorisation de Mise sur le Marché (AMM) spécifiques pour les caprins ne semblent pas prioritaires.

tionnées, commercialisé au Japon sous le nom de Nekka-Rich, à des chevreaux naturellement infectés a entraîné une réduction significative de la diarrhée chez les animaux traités par rapport à des témoins non traités (Paraud et al 2011). Ce produit permet la maîtrise des signes cliniques et autoriserait une gestion collective de la maladie. A l'inverse, aucun effet de la distribution de levures tuées sur l'excrétion de Cryptosporidium spp n'a été montré chez des chevreaux naturellement infectés (Viel et Chartier 2005).

De nombreuses lacunes persistent dans la connaissance de la cryptosporidiose chez les caprins que ce soit en épidémiologie descriptive et analytique, en caractérisation moléculaire et en moyens de maîtrise. Plusieurs études envisagées par l'Anses au Laboratoire de Niort s'attacheront à combler un certain nombre de ces manques.

\section{2 / Les nématodes gastro-intes- tinaux et les résistances aux anthelminthiques : vers une ges- tion intégrée d'une pathologie parasitaire}

Le parasitisme par des helminthes est une des principales menaces sanitaires liées à l'exploitation du pâturage par les chèvres. Les infestations par divers genres de nématodes (encore appelés strongles) qui parasitent divers organes du tractus digestif sont les plus largement répandues et fréquemment rencontrées. A l'échelle mondiale, 4 genres dominants sont signalés dans l'abomasum: (Haemonchus et Teladorsagia), l'intestin grêle (Trichostrongylus) ou le gros intestin (Oesophagostomum). L'importance de ces parasitoses tient aux pertes de production induites, à la fois sous un angle quantitatif (croissance des chevreaux, pertes de production de lait) ou qualitatif (baisse du taux butyreux du lait) (Hoste et Chartier 1993). Les formes subcliniques, chroniques sont les plus fréquentes et à l'origine de pertes économiques insidieuses, à long terme. En l'absence de mesures de contrôle, des épisodes plus aigus peuvent survenir, exprimés par des diarrhées, parfois des anémies, voire de la mortalité. Ces conséquences économiques et cliniques majeures expliquent l'impératif de maîtrise de ce parasitisme.

La gestion de ce parasitisme a longtemps reposé sur l'emploi quasi exclusif de molécules de synthèse : les anthelminthiques (AHs). Toutefois, comme pour les insecticides ou les antibiotiques, il est vite apparu que les molécules chimiques n'étaient pas la panacée contre les vers, en raison du développement rapide et de la diffusion continue de résistances aux diverses familles de 
molécules mises sur le marché dans les populations de Nématodes GastroIntestinaux (NGI) chez les petits ruminants (Waller 2006) (cf. encadré 2). De plus, parmi les ruminants domestiques, les caprins sont considérés comme particulièrement affectés par les phénomènes de résistances aux AHs lorsqu'on se fonde à la fois sur des critères de prévalence et de vitesse d'apparition des résistances aux diverses familles de molécules. Ce constat, objectivé à l'échelle mondiale (Jackson et al 2012), est aussi reflété par la situation française. Les enquêtes les plus récentes signalent des prévalences de résistance aux benzimidazoles concernant plus de $70 \%$ des exploitations surveillées, et à moindre degré au lévamisole (Paraud et al 2009a). Seules les résistances aux lactones macrocycliques n'ont pas été identifiées pour le moment, bien que des cas chez les caprins aient déjà été signalés en Europe (Jackson et al 2012). La complexité de gestion des NGI est encore aggravée chez les chèvres laitières en raison de restrictions réglementaires qui font que, parmi les 3 familles disponibles d'AHs à large spectre, seules trois molécules de la famille des benzimidazoles sont utilisables en lactation sans délai d'attente pour utiliser le lait.

La chèvre laitière apparaît donc comme un modèle où les moyens usuels de maîtrise d'une pathologie parasitaire majeure, relevant de la chimiothérapie, sont désormais sévèrement limités en raison $i$ ) des capacités d'adaptation des parasites en cause et ii) des restrictions liées à la réglementation issue de la demande sociétale. Une situation proche existe chez les ovins mais de manière moins exacerbée. Ces besoins de mâ̂trise ont souvent été traduits en problématiques scientifiques. Certaines des solutions et corrections proposées ont été construites grâce à des travaux cognitifs dans des disciplines diverses mais complémentaires (épidémiologie, parasitologie, génétique des populations, pharmacologie, phytochimie) à l'origine d'une action européenne COST (CAPARA) et apportant des informations génériques utiles aussi pour gérer ces helminthoses chez d'autres espèces (Hoste et al 2010).

a) Les facteurs expliquant la forte prévalence de résistances aux AHs chez les caprins

Le développement rapide et la large diffusion des résistances dans les populations de nématodes chez les caprins s'expliquent par plusieurs facteurs prédisposants ou par des erreurs de conduite. Leurs rôles et leurs conséquences n'ont parfois été identifiés que tardivement : i) la faible capacité des chèvres à développer une réponse immune effica- ce face aux NGI conduit les éleveurs à traiter souvent et de façon systématique tous les animaux d'un troupeau; ii) la vocation laitière des animaux et les restrictions de choix des molécules sans résidus dans le lait ont conduit à privilégier l'emploi quasi exclusif des benzimidazoles pendant la période de production, soit pendant les 10 mois de l'année correspondant aussi à la période de pâturage et de risques accrus d'infestation par les NGI ; iii) la méconnaissance de différences métaboliques, physiologiques et pharmacologiques entre ovins et caprins a amené des erreurs thérapeutiques. Pendant presque 20 ans, l'administration des AHs aux chèvres a été calculée selon des posologies fixées pour les ovins. Cette pratique a conduit à soumettre les vers à des concentrations insuffisantes de produits actifs, puisque l'action d'un $\mathrm{AH}$ est fonction de sa présence au site d'action à une concentration seuil pendant une durée suffisante. La rationalisation d'emploi des AHs chez les caprins a découlé d'une meilleure connaissance de leur devenir spécifique chez cette espèce. Des données de pharmacologie comparée ont permis d'expliquer en grande partie l'efficacité antiparasitaire réduite des principaux AHs chez la chèvre par rapport au mouton (Galtier et al 1981, Hennessy 1997, Alvinerie et al 1999, Dupuy et al 2001). Cette meilleure connaissance des spécificités métaboliques caprines a permis de corriger des erreurs qui favorisaient la sélection de populations de vers résistantes. Elles ont aussi conduit à des recommandations pratiques pour adapter les posologies en élevages caprins (Chartier 2010a).

\section{b) Comment mieux utiliser les $A H S$} chez les chèvres pour éviter les résistances?

La forte prévalence des résistances aux AHs en élevages caprins a stimulé l'émergence de travaux visant à mieux définir les règles de décision pour un usage raisonné des AHs. L'objectif général est d'en réduire globalement l'usage, de freiner ainsi l'apparition des résistances et de prolonger l'efficacité des traitements.

La première option vise à mieux répondre à la question «Qui traiter ?». Ce concept de traitement dit «sélectif» (en Anglais «Targeted Selective Treatment $=T S T \gg)$ repose sur le fait que, dans une population de ruminants à l'herbe, les nématodes ne sont pas distribués selon un modèle Gaussien normal, mais selon un modèle binomial négatif (Kenyon et al 2009). Donc, seul un petit nombre d'individus au sein d'un troupeau sont très parasités et représentent un risque élevé de contamination de l'environnement, alors que la plupart des individus ont des niveaux d'infestation compatibles avec la production. Cibler les traitements pour les animaux les plus infestés est le concept de base des TST. La pertinence de critères d'identification des animaux à risque est une des clés méthodologiques du succès de la démarche. Divers modes d'évaluation indirecte des niveaux individuels d'infestation ont été proposés, puis leur validité et leur facilité d'application ont été analysées, généralement chez les ovins puis chez les caprins. Cette évaluation repose soit sur des analyses de laboratoire, soit sur des signes subcliniques (par exemple la méthode FAMACHA évaluant de manière semi quantitative l'anémie provoquée par le vers hématophage Haemonchus, en fonction de la décoloration de la conjonctive), soit sur des critères zootechniques, soit à partir de données épidémiologiques identifiant les différences de sensibilité selon les catégories d'animaux d'un troupeau. Ainsi, en élevage laitier, les plus fortes réceptivités et sensibilités au parasitisme des chèvres primipares et des chèvres présentant un fort potentiel laitier ont conduit à proposer de traiter en priorité ces deux classes d'animaux (Hoste et al 2002). En zone Caraïbes, où les chèvres sont d'abord élevées pour la viande et compte tenu de la forte prévalence d' $H$. contortus, le système FAMACHA fait l'objet de recherches actives pour être intégré à d'autres méthodes de lutte (Mahieu et al 2007, Torres-Acosta et Hoste 2008).

Une seconde option consiste à mieux répondre à la question «Quand traiter?». En théorie, l'application des AHs associe souvent un objectif curatif et un objectif préventif, et sa décision doit d'abord dépendre d'une connaissance de la dynamique des strongyloses et des risques associés pour les animaux dans chaque élevage. En pratique, l'emploi de ces substances est souvent associé à des considérations zootechniques, notamment liées à la gestion de la reproduction. Des méthodes d'analyse des risques de type HACCP, fondées sur l'analyse de l'exploitation des pâturages ont commencé à être développées pour appuyer des décisions de traitement (Napoleone et al 2011). Cette démarche vise aussi à intégrer dans un but opérationnel les travaux portant sur la gestion «agronomique» du parasitisme dont l'objectif général est de limiter l'exposition des animaux aux larves 3 infestantes (Mahieu et Aumont 2009).

c) Des méthodes alternatives pour compléter les AHs de synthèse?

Les possibilités offertes par la sélection génétique de caprins Créoles en 
Photo 3. Les particularités de comportement alimentaire des chèvres (cueilleur/ brouteur) sont suspectées d'expliquer aussi en partie des spécificités de réponse aux infestations par des strongles (crédit photo: H. Hoste, UMR 1225 IHAP).

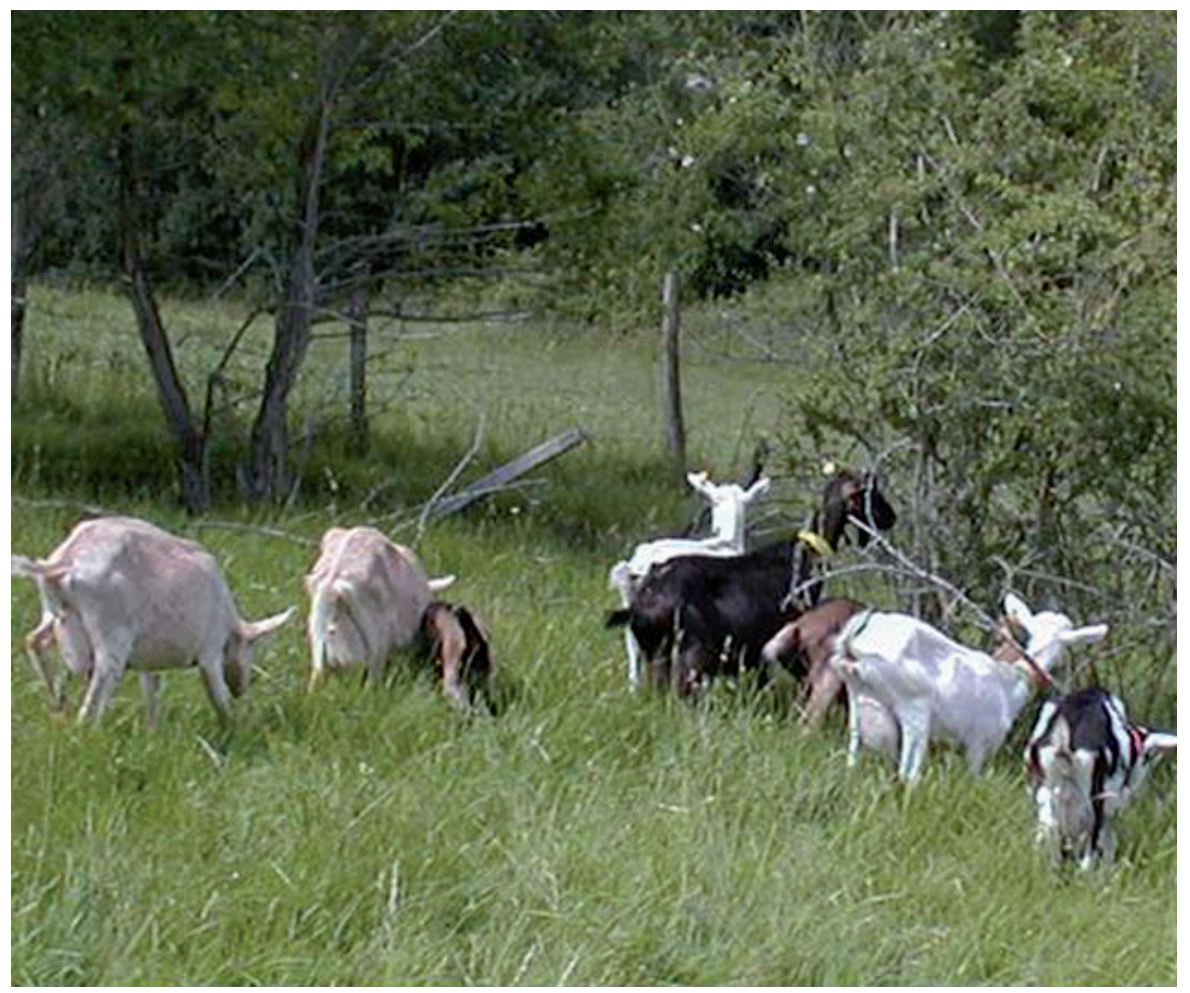

fonction de leur réponse aux NGI ont fait l'objet d'articles récents (Mandonnet et al 2006, De la Chevrotière et al 2011). De même, les concepts, la validation et les diverses modalités d'application associées à des adaptations quantitatives (complémentation protéique ou énergétique) de la ration des caprins selon le type de production (lait ou viande) et l'environnement (zones tempérées ou tropicales) ont été évoqués dans des revues récentes (Knox et al 2006, Torres-Acosta et Hoste 2008).

Un des axes actuels de recherche sur les solutions alternatives aux molécules chimiques porte sur la validation scientifique de l'activité et sur la définition des modalités d'emploi de ressources naturelles dotées de propriétés anthelminthiques, en particulier pour des légumineuses riches en tannins condensés (par exemple le sulla, le lotier corniculé ou pédonculé, ou encore le sainfoin) (Hoste et al 2006). La consommation de ces fourrages par des animaux infestés a été associée à deux effets principaux sur les vers : $i$ ) une baisse d'excrétion fécale des œufs de parasites, pouvant atteindre - 50 à - $70 \%$, qui s'explique par une baisse de fertilité des vers femelles adultes, ou par un nombre réduit de vers. Cet effet aboutit à une moindre contamination du milieu extérieur en éléments infestants ; ii) une baisse d'installation des larves 3 infestantes chez l'hôte pouvant atteindre $-70 \%$. Ces perturbations affectant le stade parasite initial expliqueraient une ne de la variabilité des effets observés. Les modifications fonctionnelles et structurelles produites chez les vers adultes et les larves infestantes ont été analysées (Brunet et al 2007, 2011). Des études in vitro et in vivo ont confirmé un rôle central joué par les tannins condensés mais d'autres flavonoïdes auraient aussi une activité (Manolaraki 2011). Compte tenu de la large distribution géographique à la fois des nématodes et des plantes à tannins, cette démarche devrait conduire à identifier des ressources exploitables (photo 3 ) pour compléter l'action des AHs chimiques dans des systèmes d'élevages caprins autres que les systèmes des zones tempérées basés sur des fourrages : systèmes pastoraux méditerranéens ou en zones tropicales.

\section{4 / Le développement d'un observatoire des maladies caprines}

Les pertes directes liées aux maladies endémiques et les conséquences potentielles de crises sanitaires liées à l'émergence de pathologies, comme l'illustre l'épisode récent de fièvre $Q$ aux PaysBas (Van der Hoek et al 2010), sont clairement ressenties par les acteurs de la filière caprine. Plusieurs enquêtes ont permis d'aborder les causes de réformes, de mortalité et les dépenses de maîtrise de la santé (Malher et Vasseur 1999, Mercier et Malher 2002, Bousquet 2005), mais aucun dispositif ne permet jusqu'à présent d'identifier les pathologies dominantes et de suivre leur évolution. De même, la capacité de détection de phénomènes émergents paraît limitée du fait de l'absence d'analyse globale des indicateurs sanitaires et des faiblesses d'encadrement sanitaire des éleveurs caprins. Dans ce contexte, les organismes à vocation sanitaire et les acteurs de la filière réunis au sein de la commission sanitaire caprine du Poitou-Charentes ont sollicité la création d'un Observatoire des MAladies CAPrines (OMACAP) pour leur fournir les éléments d'aide à la décision permettant de prioriser les actions collectives de lutte et de suivre leur efficacité, pour engager des investigations ciblées ou pour déclencher l'alerte face à un événement inhabituel. Ce projet est animé par l'Anses Laboratoire de Niort et bénéficie de l'appui financier du Conseil Régional de Poitou-Charentes pour la phase d'étude de faisabilité programmée entre 2010 et 2012 (Chartier 2010b).

Le premier objectif de l'OMACAP est d'identifier et de suivre les pathologies dominantes de la filière. Cet objectif général nécessite de compiler différentes sources de données sanitaires pour aborder l'ensemble des pathologies 
auxquelles les élevages sont confrontés, en apportant des éléments précis sur la morbidité, la mortalité et les étiologies associées à ces pathologies. Un état des lieux exhaustif des données sanitaires disponibles a permis d'identifier trois types d'acteurs pouvant répondre de façon complémentaire à cet objectif, à savoir les vétérinaires, les laboratoires de diagnostic et les éleveurs. Certaines règles ont permis de guider la construction des dispositifs correspondant et ainsi de favoriser leur fonctionnalité et la fiabilité des résultats produits (Dufour et Hendrikx 2007).

La conception des outils de saisie et la formation des acteurs de la surveillance à leur utilisation sont des étapes cruciales pour garantir la standardisation et la validité des données collectées. La définition des cas devant être enregistrés est notamment essentielle pour assurer que toutes les données soient comparables entre elles et indépendantes de la subjectivité du collecteur de l'information. La simplicité des procédures de saisie et de transfert, la régularité des retours et leur adéquation avec les attentes des participants sont autant d'éléments à respecter pour favoriser une adhésion pérenne d'un nombre suffisant d'acteurs aux dispositifs d'épidémio-surveillance. La participation des acteurs étant volontaire et non déterminée par un échantillonnage aléatoire, la représentativité de l'échantillon étudié est par définition imparfaite. Les biais de représentativité doivent donc tendre à être limités par une diversification des types d'élevages échantillonnés et à défaut, la description précise des élevages concernés doit permettre de caractériser la population étudiée.

La formalisation du fonctionnement de l'OMACAP est également indispensable pour clarifier le rôle de chaque partenaire et éviter les dysfonctionnements. Pour chaque dispositif, un protocole détaille l'ensemble des modalités de fonctionnement et chaque adhérent est signataire d'une charte précisant ses droits et ses devoirs. Le fonctionnement général de l'observatoire est régulé par une charte signée par les principaux organismes partenaires représentés au niveau d'un comité d'orientation. Ce comité est chargé d'examiner les informations produites et de garantir leur adéquation avec les perspectives d'action des pro- fessionnels impliqués dans la gestion des maladies caprines.

Dans le domaine de la recherche, plusieurs synergies sont envisageables en lien avec les actions de surveillance. Le suivi des performances zootechniques et sanitaires des troupeaux dans le cadre d'expérimentations pourrait utiliser la méthodologie d'évaluation standardisée d'indicateurs du statut sanitaire des élevages, et ainsi devenir une source d'information complémentaire pour l'OMACAP. Réciproquement, les résultats pourraient orienter le choix des questions prioritaires de recherche pour l'optimisation des mesures de lutte.

Après quelques mois de fonctionnement, l'OMACAP apporte des éléments nouveaux pour évaluer l'importance relative et les causes des pathologies associées aux diverses types d'élevages rencontrés en Poitou-Charentes, principalement de grands élevages livreurs de lait vers des industriels transformateurs. Le deuxième objectif vise à compléter ces résultats par des enquêtes sur la répartition des pathologies dominantes et des facteurs de risque associés. Le troisième objectif est de développer une épidémio-surveillance vis-à-vis de pathologies émergentes. Il pourra être développé à partir des réseaux d'acteurs mis en place, mais cette fois pour la notification des cas atypiques, par exemple sur le modèle du système «émergences» (Vourc'h et Barnouin 2003) et également par d'autres dispositifs de surveillance syndromique moins spécifiques mais plus systématiques et donc potentiellement plus sensibles, comme l'observatoire de la mortalité des ruminants (Perrin et al 2011). Si l'étude de faisabilité régionale montre des résultats favorables, l'observatoire pourra être étendu au niveau national et intégrer d'autres types d'élevages, notamment des élevages fermiers en système pâturant.

\section{Conclusion}

La structure de cet article se fonde sur la classification usuelle des principaux agents pathogènes impliqués. Toutefois, il peut aussi être lu sous différents angles qui, dans une démarche comparative avec la production ovine, illustrent l'intérêt des recherches spécifiques sur les caprins afin de mieux comprendre et analyser les processus physiopathologiques en cause, en situer les conséquences en lien avec la production, et adapter les modes de contrôle de ces pathologies.

Les recherches décrites dans cet article sont à positionner dans le contexte du principal objectif de production caprine en Europe qui est le lait. Dans ce cadre économique, l'animal cible est la chèvre adulte, le chevreau étant considéré comme un sous-produit, à l'exception des objectifs de renouvellement et d'amélioration génétique du troupeau par les chevrettes. Ce constat explique pourquoi cinq des six pathologies évoquées concernent d'abord les caprins adultes et non les jeunes. Par ailleurs, les thématiques retenues illustrent les principaux enjeux en santé animale (Ducrot et al 2010) : en premier lieu un enjeu de santé publique (infections mammaires, paratuberculose, maladies à prions et cryptosporidiose), mais aussi par les conséquences économiques, des enjeux pour le bien être animal et l'environnement, afin de limiter l'usage d'intrants chimiques en élevage (infections mammaires et strongyloses gastrointestinales). Dans ce cadre zootechnique, les recherches en pathologie caprine ne sont plus perçues comme étant «à la traîne» des recherches sur les ovins, mais bien plus comme un modèle original d'étude de pathologies majeures, prenant en compte les objectifs et les contraintes principales des filières de production laitière chez les petits ruminants et proposant des modalités innovantes de gestion sanitaire.

Dans le choix des pathologies décrites, il faut souligner à la fois $i$ ) la communauté ou la proximité (cf. virus CAEV et MVV) des agents pathogènes entre caprins et ovins et ii) dans de nombreux cas, des différences notables dans les processus morbides entre les deux espèces de petits ruminants. Ces éléments illustrent l'intérêt fondamental de développer des études sur les caprins comme modèle de pathologie comparée pour mieux appréhender les mécanismes pathogéniques chez les ovins, voire les bovins, et pour aborder des thématiques fondamentales en biologie (barrière d'espèce, adaptation des pathogènes, compromis entre immunité et comportement). 


\section{Références}

Alvinerie M., Lacoste E., Sutra J.F., Chartier C., 1999. Some pharmacokinetic parameters of eprinomectin in goats following pour-on administration. Vet. Res. Commun., 23, 449-55.

Andreoletti O., Morel N., Lacroux C., Rouillon V., Barc C., Tabouret G., Sarradin P., Berthon P., Bernardet P., Mathey J., Lugan S., Costes P., Corbière F., Espinosa J.C., Torres J.M., Grass J., Schelcher F., Lantier F., 2006. Bovine spongiform encephalopathy agent in spleen from an ARR/ ARR orally exposed sheep. J. Gen. Virol., 87, 1043-1046.

Barillet F., Mariat D., Amigues Y., Faugeras R., Caillat H., Moazami-Goudrazi K., Rupp R., Babilliot J.M., Lacroux C., Lugan S., Schelcher F., Chartier C., Corbière F., Andreoletti O., Perrin-Chauvineau C., 2009. Identification of seven haplotypes of the caprine PrP gene at codons $127,142,154,211,222$ and 240 in French Alpine and Saanen breeds and their association with classical scrapie. J. Gen. Virol., 90, 769-776.

Baudry C., de Crémoux R., Chartier C. Perrin G., 1997. Incidence de la concentration cellulaire du lait de chèvre sur sa production et sa composition. Vet. Res., 28, 277-286.

Baudry C., Mercier P., Mallereau M.P., Lenfant D., 1999. Utilisation des numérations cellulaires individuelles pour la détection des infections mammaires subcliniques de la chèvre : définition des seuils. In : Milking and milk production of dairy sheep and goats. EAAP Publication, $6^{\text {th }}$ Int. Symp. Milking Small Rum., 95, 119-123.

Bergonier D., de Crémoux R., Lagriffoul G., Rupp R., Berthelot X., 2002. Mammites non mycoplasmiques des petits ruminants. Etiologie et épidémiologie des mammites. Le Point Vet., 33, 40-45.

Bergonier D., de Crémoux R., Rupp R., Lagriffoul G., Berthelot X., 2003. Mastitis of dairy small ruminants. Vet. Res., 34, 689-716.

Bergonier D., de Crémoux R., Berthelot X., 2010. Spécificités du traitement au tarissement chez les petits ruminants. Bull. GTV., 56, 15-26.

Billinis C., Panagiotidis C.H., Psychas V., Argyroudis S., Nicolaou A., Leontides S., Papadopoulos O., Sklaviadis T., 2002. Prion protein gene polymorphisms in natural goat scrapie. J. Gen. Virol., 83, 713-21.

Billon P., Fernandez Martinez N., Ronningen O., Sangiorgi F., Schuiling E., 2002. Quantitative requirements for milking installations for small ruminants. I.D.F. Bulletin, 370, 4-19.

Blacklaws B.A., Berriatua E., Torsteinsdottir S., Watt N.J., de Andres D., Klein D., Harkiss G.D., 2004. Transmission of small ruminant lentiviruses. Vet. Microbiol., 101, 199-208.

Bousquet C., 2005. Pathologie caprine en Deux-Sèvres : état des lieux et impact sur les niveaux de réforme et de mortalité. Thèse Méd. Vét., Ecole Nationale Vétérinaire de Toulouse, France, 153p.

Branscum A.J., Gardner I.A., Johnson W.O., 2005. Estimation of diagnostic-test sensitivity and specificity through Bayesian modelling. Prev. Vet. Med., 68, 145-163.

Bruce M.E., Will R.G., Ironside J.W., McConnell I., Drummond D., Suttie A.,
McCardle L., Chree A., Hope J., Birkett C., Cousens S., Fraser H., Bostock C.J., 1997. Transmissions to mice indicate that "new variant' CJD is caused by the BSE agent. Nature, 389, 498-501.

Brunet S., Aufrère J., El Babili F., Fouraste I. Hoste H., 2007. The kinetics of exsheathment of infective nematode larvae is disturbed in presence of tannin rich plant (sainfoin) both in vitro and in vivo. Parasitology, 134, 12531262

Brunet S., Fourquaux I., Hoste H., 2011. Ultrastructural changes in the infective thirdstage larvae of parasitic nematodes of ruminants treated with a sainfoin (Onobrychis viciifolia) extract. Parasitol. Int., 60, 419-424.

Cama V., Cabrera L., Lopera C., Vargas M. Taquiri C., Smit H., Xiao L., 2008. Molecula characterization of Cryptosporidium and microsporidia from goats and sheep in Peru, abstr. PL3. Abstr. 10 ${ }^{\text {th }}$ Int. Workshop on Opportun. Protists, Boston, USA.

Castro-Hermida J.A., Delafosse A., Pors I., Ares-Mazás E., Chartier C., 2005. Giardia duodenalis and Cryptosporidium parvum infections in adult goats and their implications for neonatal kids. Vet. Rech., 157, 623-627.

Castro-Hermida J.A., Almeida A., González Warleta M., Correia da Costa J., 2007. Occurrence of Cryptosporidium parvum and Giardia duodenalis in healthy adult domestic ruminants. Parasitol. Res., 101, 1443-1448.

Cebo C., Caillat H., Bouvier F., Martin P. Rupp R., 2009. Composition de la fraction protéique de la membrane du globule gras et résistance aux mammites chez les caprins. Renc. Rech. Rum., 16, 302.

Chartier C., Mallereau M.P., Lenfant D., 1999. Efficacité du lactate d'halofuginone dans la prévention de la cryptosporidiose chez le chevreau nouveau-né. Rev. Méd. Vét., 150, 341-348.

Chartier C., 2010a. «Pathologie caprine : du diagnostic à la prévention». Le Point Vétérinaire $(\mathrm{Ed}), 323 \mathrm{p}$.

Chartier C., 2010b. Mise en place d'un observatoire régional des maladies caprines. L'egide, 59, 1.

Clément V., Caillat H., Piacère A., Manfredi E., Robert-Granié C., Bouvier F., Rupp R., 2008. Vers la mise en place d'une sélection pour la résistance aux mammites chez les caprins laitiers. Renc. Rech. Rum., 15, 405-408.

Collectif, 2006. Installations de traite pour les chèvres. Editions France Agricole, Collection produire mieux, 156p.

Collinge J., Sidle K.C., Meads J., Ironside J., Hill A.F., 1996. Molecular analysis of prion strain variation and the aetiology of "new variant' CJD. Nature, 383, 685-90.

Crémoux de R., Poutrel B., 2000. Les numérations cellulaires chez la chèvre : un outil de diagnostic présomptif des infections mammaires. In : $7^{\text {th }}$ Int. Conf. on Goats, Tours, France, 757-760.

Crémoux de R., Heuchel V., Poutrel B., Pillet R., Perrin G., 1996. Utilisation des numérations cellulaires pour le diagnostic des infections mammaires d'origine bactérienne chez la chèvre. In : Somatic cells and milk of small ruminants. Rubino R. (Ed). Proc. Int. Symp.
Somatic cells and milk of small ruminants. Bella, Italie, 35-39.

Crémoux de R., Heuchel V., Chatelin Y.M. 2001. Evaluation de stratégies de contrôle des comptages de cellules somatiques des laits de mélange en élevage caprin. Renc. Rech. Rum., 8, 157-160.

Chevrotière de la C., Moreno C., Jacquiet P. Mandonnet N., 2011. La sélection génétique pour la maîtrise des strongyloses gastro-intestinales des petits ruminants. INRA Prod. Anim., 24, 221-234.

Delafosse A., Castro-Hermida J.A., Baudry C., Ares-Mazás E., Chartier C., 2006. Herdlevel risk factors for Cryptosporidium infection in dairy-goat kids in western France. Prev. Vet. Med., 77, 109-121.

Díaz P., Quílez J., Robinson G., Chalmers R.M., Díez-Baños P., Morrondo P., 2010. Identification of Cryptosporidium xiaoi in diarrhoeic goat kids (Capra hircus) in Spain. Vet. Parasitol., 172, 132-134.

Ducrot C., Bed'Hom B., Beringue V., Coulon J.B., Fourichon C., Guérin J.L, Krebs S., Rainard P., Sarradin P., Schwartz I., Torny D., Vayssier-Taussat M.L., Zientara S., Zundel E., 2010. Enjeux et spécificités de la recherche en santé animale. INRA Prod. Anim., 23, 359368 .

Dufour B., Hendrikx P., 2007. Surveillance épidémiologique en santé animale. $2^{\text {ème }}$ Edition. Editions Quae, Paris, France, 289p.

Dupuy J., Chartier C., Sutra J.F., Alvinerie M., 2001 Eprinomectin in dairy goats: dose influence on plasma levels and excretion in milk. Parasitol. Res., 87, 294-8.

Eloit M., Adjou K., Coulpier M., Fontaine J.J., Hamel R., Lilin T., Messiaen T., Baron T., Bencsik A., Anne Biacabe G., Beringue V., Laude H., Le Dur A., Vilotte J.L., Comoy E., Deslys J.P., Grassi J., Simon S., Lantier F., Sarradin P., 2005. BSE agent signatures in a goat. Vet. Rec., 156, 523-524.

Elsen J.M., Amigues Y., Schelcher F., Ducrocq V., Andréoletti O., Eychenne F., Khang J.V., Poivey J.P., Lantier F., Laplanche J.L., 1999. Genetic susceptibility and transmission factors in scrapie: detailed analysis of an epidemic in a closed flock of Romanov. Arch. Virol., 144, 431-45.

Erhouma E., Guiguen F., Chebloune Y., Gauthier D., Lakhal L.M., Greenland T., Morneix J.F., Leroux C., Alogninouwa T., 2008. Small ruminant lentivirus proviral sequences from wild ibexes in contact with domestic goats. J. Gen. Virol., 89, 1478-1484.

Fediaevsky A., Tongue S.C., Noremark M. Calavas D., Ru G., Hopp P., 2008. A descriptive study of the prevalence of atypical and classical scrapie in sheep in 20 European countries. BMC Vet. Res., 4, 1-24.

Galtier P., Escoula L., Camguilhem R., Alvinerie M., 1981. Comparative availability of levamisole in non lactating ewes and goats. Ann. Rech. Vet., 12, 109-115.

Gay-Jacquin M.F., Jaubert G., Jaubert A., 1996. Cellules somatiques et traitements technologiques du lait de chèvre. In : Somatic cells and milk of small ruminants. Rubino R. (Ed). Proc. Int. Symp. Somatic cells and milk of small ruminants. Bella, Italie, 313-317. 
Geurden T., Thomas P., Casaert S., Vercruysse J., Claerebout E., 2008. Prevalence and molecular characterisation of Cryptosporidium and Giardia in lambs and goat kids in Belgium. Vet. Parasitol., 155, 142-145.

Groschup M.H., Lacroux C., Buschmann A., Lühken G., Mathey J., Eiden M., Lugan S., Hoffmann C., Espinosa J.C., Baron T., Torres J.M., Erhardt G., Andreoletti O., 2007. Classic scrapie in sheep with the ARR/ARR prion genotype in Germany and France. Emerg. Infect. Dis., 13, 1201-1207.

Hagenaars T.J., Melchior M.B., Bossers A., Davidse A., Engel B., van Zijderveld F.G., 2008. Scrapie prevalence in sheep of susceptible genotype is declining in a population subject to breeding for resistance. BMC Vet. Res. $6,1-11$.

Hennessy D.R., 1997. Physiology, pharmacology and parasitology. Int. J. Parasitol., 27, 145-152.

Hoste H., Chartier C., 1993. Comparison of the effects on milk production of concurrent infection with Haemonchus contortus and Trichostrongylus colubriformis in high- and ow-producing dairy goats. Am. J. Vet. Res. 54, 1886-1893.

Hoste H., Chartier C., Lefrileux Y., 2002. Control of gastro intestinal parasitism with nematodes in dairy goats by treating the host category at risk. Vet. Res., 33, 531-546.

Hoste H., Jackson F.J., Athanasiadou S., Thamsborg S., Hoskin S.O., 2006. The effects of tannin-rich plants on parasitic nematodes in ruminants. Trends Parasitol., 22, 253-261.

Hoste H., Sotiraki S., Landau S.Y., Jackson F., Beveridge I., 2010. Goat nematode interactions: think differently! Trends Parasitol., 26, 376-381.

Hötzel I., Cheevers W.P., 2001. Host range of small ruminant lentivirus cytopathic variants determined with a selectable caprine arthritisencephalitis virus pseudotype system. J. Virol., 75, 7384-7391.

Houston F, Goldmann W, Chong A. Jeffrey M., González L., Foster J., Parnham D. Hunter N., 2003. Prion diseases: BSE in sheep bred for resistance to infection. Nature, 423, p498.

Hunter N., Goldmann W., Foster J.D., Cairns D., Smith G., 1997. Natural scrapie and PrP genotype: case-control studies in British sheep. Vet. Rec., 141, 137-40.

Jackson F.J., Varady M., Bartley D., 2012. Managing anthelmintic resistance in goats Can we learn lessons from sheep? Small Rum. Res.,103, 3-9.

Jaubert G., Gay-Jacquin M.F., Perrin G., 1996. Numérations cellulaires et caractéristiques biochimiques et technologiques du lait de chèvre. In : Somatic cells and milk of small ruminants. Rubino R. (Ed). Proc. Int. Symp. Somatic cells and milk of small ruminants. Bella, Italie, 263-268.

Kenyon F., Greer A.W., Coles G.C., Cringoli G., Papadopoulos E., Cabaret J., Berrag B. Varady M., van Wyk J., Thomas E., Vercruysse J., Jackson F.J., 2009. The role of targeted selective treatments in the development of refugia-based approaches to the control of gastrointestinal nematodes of small ruminants. Vet. Parasitol., 164, 3-11.

Knox M.R., Torres-Acosta J.F.J., AguilarCaballero A.J., 2006. Exploiting the effect of dietary supplementation of small ruminants on resilience and resistance against gastrointestinal nematodes. Vet. Parasitol., 139, 385 393.

Lacerenza D., Giammarioli M., Grego E., Marini C., Profiti M., Rutili D., Rosati S. 2006. Antibody response in sheep experimentally infected with different small ruminant lentivirus genotypes. Vet. Immunol. Immunopath., 112, 264-271.

Lefrileux Y., Pommaret A., Raynaud S., 2008 Impacts de la monotraite dans une exploitation caprine fromagère à haut niveau de production. Renc. Rech. Rum., 15, 167-170.

Mandonnet N., Menendez-Buxadera A. Arquet R., Mahieu M., Bachand M., Aumont G., 2006. Genetic variability in resistance to gastrointestinal strongyles during early lactation in Creole goats. Anim. Sci., 82, 283-287.

Mahieu M., Arquet R., Kandassany T., Mandonnet N., Hoste H., 2007. Evaluation of targeted drenching using FAMACHA method in Creole goats: reduction of anthelmintic use and effects on kid production and pasture contamination. Vet. Parasitol., 146, 135-147.

Mahieu M., Aumont G., 2009. Effects of sheep and cattle alternate grazing on sheep parasitism and production. Trop. Anim. Health Prod., 41, 229-239.

Malher X., Vasseur C., 1999. Les dépenses de maîtrise de la santé dans les troupeaux caprins laitiers de Vendée et de Maine-et-Loire. Bull. GTV, 3, 63-68.

Manolaraki F., 2011. Propriétés anthelminthiques du sainfoin (Onobrychis viciifoliae) Analyse des facteurs de variations et du rôle des composés phénoliques impliqués. Thèse d'Université, Toulouse, France.

Marnet P.G., 1998. Physiologie de 1'éjection du lait et importance pour la lactation. Renc. Rech. Rum., 5, 313-320.

Marnet P.G., Komara M., 2008. Management systems with extended milking intervals in ruminants: regulations of production and quality of milk. J. Anim. Sci., 86, 47-56.

Melchior M.B., Windig J.J., Hagenaars T.J., Bossers A., Davidse A., van Zijderveld F.G., 2008. Eradication of scrapie with selective breeding: are we nearly there? BMC Vet. Res., 6, 24

Mercier P., Mahler X., 2002. Dominantes de la pathologie caprine en élevage laitier. Le Point Vet., 33, 23-25.

Mercier P., Baudry C., Martin J., Bertin C., Laroucau K., Beaudeau F., Seegers H., Malher X., 2007. Utilisation des techniques bayésiennes pour estimer les caractéristiques de deux tests de diagnostic de la paratuberculose caprine. Epidémiol. Santé Anim., 51, 57-64.

Mercier P., Baudry C., Martin J., Bertin C. Laroucau K., Beaudeau F., Seegers H., Malher X., 2009a. Utilisation des techniques bayésiennes pour estimer les caractéristiques de deux tests de diagnostic de la paratuberculose caprin (erratum). Epidémiol. Santé Anim., 56, 255-256.

Mercier P., Beaudeau F., Laroucau K., Bertin C., Boschiroli M.L., Baudry C., Seegers H. Malher X., 2009b. Comparative age-related responses to serological and faecal tests directed to Mycobacterium avium paratuberculosis (Map) in French dairy goats. Small Rum. Res., $87,50-56$

Mercier P., Baudry C., Beaudeau F., Seegers H., Malher X., 2010. Estimated prevalence of
Mycobacterium avium subspecies paratuberculosis infection in herds of dairy goats in France. Vet. Rec., 167, 412-415.

Moreno C.R., Moazami-Goudarzi K. Laurent P., Cazeau G., Andreoletti O., Chadi S., Elsen J.M., Calavas D., 2007. Which PrP haplotypes in a French sheep population are the most susceptible to a typical scrapie? Arch. Virol., 152, 1229-32

Morgan F., Gaspard C.E., 1999. Influence des cellules somatiques sur les qualités technologiques du lait de chèvre et sur les caractéristiques des fromages de chèvre. Renc. Rech Rum., 6, 37.

Moum T., Olsaker I., Hopp P., Moldal T., Valheim M., Benestad S. L., 2005. Polymorphisms at codons 141 and 154 in the ovine prion protein gene are associated with scrapie Nor98 cases. J. Gen. Virol., 86, 231-5

Napoleone M., Lefrileux Y., Hoste H., 2011. The use of grazing pastures in goat production: development of an approach to combine optimized use of the forage resource and the control of related risks. In: New trends for Innovation in the Mediterranean Animal production. Bouche R., Derkimba A., Casabianca F. (Eds). EAAP Publication, 129, 307-316.

Oskarsson T., Hreggvidsdottir H.S., Agnarsdottir G., Matthiasdottir S., Ogmundsdottir M.H., Jonsson S.R., Georgsson G., Ingvarsson S., Andresson O.S., Andresdottir V., 2007. Duplicated sequence motif in the long terminal repeat of maedi-visna virus extends cell tropism and is associated with neurovirulence. $\mathrm{J}$ Virol., 81, 4052-4057.

Papasavva-Stylianou P., Kleanthous M. Toumazos P., Mavrikiou P., Loucaides P., 2007. Novel polymorphisms at codons 146 and 151 in the prion protein gene of Cyprus goats, and their association with natural scrapie. Vet. J., 173, 459-462.

Paraud C., Guyot K., Chartier C., 2009. Prevalence and molecular characterization of Cryptosporidium sp. infection in calves, lambs and goat kids reared in a same farm in France. III International Giardia and Cryptosporidium Conference, Orvieto, Italy.

Paraud C., Kulo A., Pors I., Chartier C., 2009. Resistance of goat nematodes to multiple anthelmintics on a farm in France. Vet. Rec., 164, 563-564.

Paraud C., Chebroux C., Chartier C., 2010 Méthodes d'élevage des chevreaux en relation avec le risque de cryptosporidiose-Enquête descriptive dans les Deux-Sèvres. Renc. Rech. Rum., 17, 95.

Paraud C., Pors I, Journal J.P., Besnier P. Reisdorffer L., Chartier C., 2011. Control of cryptosporidiosis in neonatal goat kids: efficacy of a product containing activated charcoal and wood vinegar liquid (Obionekk) in field conditions. Vet. Parasitol, 180, 354-357.

Perrin J.B., Hendrikx P., Vinard J.L. Ducrot C., Calavas D., 2011. Surveillance of cattle population through real-time mortality monitoring. Epidémiol. Santé Anim., 22, 5960

Pisoni G., Bertoni G., Puricelli M., Maccalli M., Moroni P., 2007. Demonstration of coinfection with and recombination by caprine arthritis-encephalitis virus and Maedi-Visna virus in naturally infected goats. J. Virol., 81, 4948-4955.

Pisoni G., Bertoni G., Manarolla G., Vogt H.R., Scaccabarozzi L., Locatelli C., Moroni 
P., 2010. Genetic analysis of small ruminant lentiviruses following lactogenic transmission. Virology, 407, 91-99.

Prusiner S.B., 1982. Novel proteinaceous infectious particles cause scrapie. Science, 216 136-144

Prusiner S.B., 1988. Molecular structure, biology, and genetics of prions. Adv. Virus Res., 35, 83-136.

Quílez J., Torres E., Chalmers R.M., Hadfield S.J., del Cacho E., Sánchez-Acedo C., 2008. Cryptosporidium genotypes and subtypes in lambs and goat kids in Spain. Appl. Env. Microbiol., 74, 6026-6031.

Raynal-Ljutovac K., Pirisi A., de Crémoux R., Gonzalo C., 2007. Somatic cells of goat and sheep milk: analytical, sanitary, productive and technological aspects. Small Rum. Res., 68, 126-144.

Rupp R., Clément V., Piacère A., RobertGranié C., Manfredi E., 2011. Genetic parameters for milk somatic cell score and relationship with production and udder type traits in dairy Alpine and Saanen primiparous goats. J. Dairy Sci., 94, 3629-3634.
Smith M.C., Shermann D.M., 1994. Goat Medicine. Lea and Febiger Eds, Malvern, USA, 694p.

Stehman S.M., 1996. Paratuberculosis in small ruminants, deer, and South American camelids. Vet. Clin. North Am. Food Anim. Pract., 12, 441-455.

Torres-Acosta J.F.J., Hoste H., 2008. Alternative or improved methods to limit gastrointestinal parasitism in grazing/browsing sheep and goats. Small Rum. Res., 77, 159-173.

Vaccari G., Di Bari M.A., Morelli L., Nonno R., Chiappini B., Antonucci G., Marcon S., Esposito E., Fazzi P., 2006. Identification of an allelic variant of the goat PrP gene associated with resistance to scrapie. J. Gen. Virol., 87, 1395-402.

Van der Hoek W., Dijkstra F., Schimmer B., Schneeberger P. M., Vellema P., Wijkmans C. ter Schegget R., Hackert V., van Duynhoven Y., 2010. Q fever in the Netherlands: an update on the epidemiology and control measures. Euro Surveill., 15 online:http://www.eurosurveillance.org/ ArticleId=19520.

Vialard J., 2002. Epidémiologie de la paratu- berculose. Bull. GTV., numéro hors série, Paratuberculose des Ruminants, 6-11.

Viel H., Chartier C., 2005. Cryptosporidiose et croissance du jeune chevreau. Efficacité du lactate d'halofuginone et des ferments lactiques sur l'excrétion d'oocystes. Bull. GTV., 28, 203-207.

Vourc'h G., Barnouin J., 2003. How to improve the detection of animal emerging diseases? A two-level (veterinarian/farmer) approach based on an internet-oracle database. In: Proc. $10^{\text {th }}$ Int. Symp. Vet. Epidemiol, Vina del Mar, Chile, 4p.

Waller P.J., 2006. From discovery to development: current industry perspectives for the development of novel methods of helminth control in livestock. Vet. Parasitol., 139, 1-14.

Wood J.N., Done S.H., Pritchard G.C., Wooldridge M.J., 1992. Natural scrapie in goats: case histories and clinical signs. Vet. Res., 131, 66-68.

Xiao L., 2010. Molecular epidemiology of cryptosporidiosis: An update. Exp. Parasitol., $124,80-89$.

\title{
Résumé
}

Les enjeux économiques liés à l'espèce caprine en Europe paraissent mineurs par rapport à ceux des filières ovines et bovines et pourraient limiter l'intérêt de recherches spécifiques en pathologie caprine. C'est pourquoi, en se fondant sur des exemples de pathologies dues aux principales classes d'agents pathogènes (prions, virus, bactéries, parasites protozoaires et helminthes) affectant les caprins et leur filière de production, cet article présente les principales recherches menées en France, les données actuelles disponibles sur la compréhension des mécanismes pathogéniques et des processus physiopathologiques, ainsi que sur le développement de gestions innovantes de ces pathologies. Il a aussi pour objectif d'illustrer l'intérêt d'études spécifiques sur les chèvres non seulement en termes de pathologie comparée chez les petits ruminants, mais aussi pour prendre en considération les contraintes d'une filière économique dynamique.

\begin{abstract}
Research in goat pathology: applications and perspectives

Within Europe, the goat industry appears to have minor importance when compared to sheep or cattle productions, and the interest of research and studies in caprine pathology is limited. Here, this article is aimed at presenting the main research models in France, the current available data on the pathogenic mechanisms and the physiopathological processes and the related development of measures of management control using examples of pathologies caused by different agents (prions, viruses, bacteria, protozoan or helminthic parasites) that affect goats and their production. It is also aimed at underlining the interest of specific caprine studies not only as models of comparative pathology in small ruminants but also as tools that take into account the specific constraints of the dairy industry.
\end{abstract}

HOSTE H., EHRHARDT N., PARAUD C., RIEUX A., MERCIER P., VALAS S., ANDREOLETTI O., CORBIÈRE F., SCHELCHER F., LACROUX C., de CRÉMOUX R., ALVINERIE M., CHARTIER C., 2012. Recherche en pathologie caprine : applications et perspectives. In : Elevage caprin. Baumont R., Sauvant D. (Eds). Dossier, INRA Prod. Anim., 25, 245258 . 